\title{
Transurethral Resection of the Prostate A 3 Year Experience
}

\section{NO Chukwujama \\ T Oguike \\ J Azike}

Department of Surgery

Imo State University Teaching

Hospital

Orlu, Imo State.

\author{
All Correspondence: \\ Dr NOChukwujama \\ Department of Surgery \\ Imo State University Teaching \\ Hospital, \\ P.M.B. 08, Orlu,
}

\section{E mail:}

nzubechuks@yahoo.com

\begin{abstract}
Background: Transurethral resection of the prostate (TURP) is considered the 'gold standard' in the surgical management of bladder outlet obstruction secondary to benign prostatic hyperplasia and advanced carcinoma of the prostate. The procedure is however still not routinely available in most public health institutions in Nigeria. We present our experience with this treatment modality over a three year period
\end{abstract}

Methods: The records of patients who underwent TURP over a period of three years (April 2006 May 2009) were examined. The biodata, Laboratory investigations, detail of the surgical procedure and outcome were extracted and analysed

Results: The records of forty three patients were examined. The age range was $4976 y r s$ (mean 65yrs +/- 5.8 SD). The prostate specific antigen ranged from 1.3 $50.3 \mathrm{ng} / \mathrm{ml}$ (mean $13.3+/-12.8$ ). The mean prostate size was $59 \mathrm{~g}+/-20 \mathrm{SD}$ (range 27 98grams). The indications for the surgery included refractory acute urinary retention $48.8 \%$, failed medical treatment $21 \%$, recurrent UTI $16 \%$, recurrent haematuria $9 \%$, chronic urinary retention $2 \%$. The mean duration of surgery was $80.5 \mathrm{mins}+/-14 \mathrm{SD}$ (range $60120 \mathrm{mins}$ ). The period of hospital stay ranged from 332 days (mean 8.7 days $+/-7.7 \mathrm{SD}$ ). Complications included capsular perforation in 2 patients, TURP syndrome in 2 patients, total incontinence in 1 patient and failure to void in 2 patients. Most patients (93\%) had satisfactory voiding and insignificant post void residual urine volume during subsequent follow up visits

\section{Conclusion:}

Transurethral resection of prostate is a safe and effective treatment modality in the surgical management of men with bladder outlet obstruction secondary to $\mathrm{BPH}$ and advanced CAP in our environment.

Key Words: Transurethral, Resection, Prostate, Experience

\section{Introduction}

$\mathrm{T}$ ransurethral resection of the prostate (TURP) was developed in the United States of America in the 1920s and $1930 \mathrm{~s}^{1}$. Over the years, TURP as a treatment modality for obstructing benign prostatic hyperplasia $(\mathrm{BPH})$ gained popularity throughout the world and became the gold standard of surgical treatment of $B P \mathrm{H}^{1-3}$ ] TURP is associated with both subjective and objective success rates of $85 \%$ and $90 \%$ respectively ${ }^{4}$. It offers improved rates of morbidity and mortality over and above open prostatectomy. This is in fact the main driving force behind the introduction of TURP ${ }^{5-8}$

The most common reasons to intervene in patients with $\mathrm{BPH}$ are that the symptoms are moderate to severe, bothersome and interfere with the patient's quality of life. In such patients, the absolute indications for surgery include refractory urinary retention, recurrent urinary retention, recurrent haematuria and azotemia. ${ }^{1}$

Minimal('English Channel') TURP is especially suited for patients with bladder outlet obstruction secondary to advanced carcinoma of the prostate where open surgery is in fact contradicted. In this setting, it is used as an adjunct to hormonal treatment. 9,10

Recently the place of TURP as a gold standard has been called to question in the light of development of less invasive interventional methods such as transurethral microwave thermotherapy, Holmium YAG enucleation of the prostate and Transurethral vapour resection of the prostate. These are said to present a lower complication profile but at the cost of decreased efficacy. ${ }^{11-13}$

For the Urologist in our subregion, there are numerous challenges. Despite the increasing role of TURP globally, the procedure is still not routinely available in most of our public institutions mainly due 
to high cost of setting up and the lack of the political will on the part of administrators to provide the necessary infrastructure and manpower training needed.

Even where the procedure is available, affordability may not be assured especially among the low income group without any medical insurance cover. Furthermore it has been hypothesized that blacks present with prostate glands of relatively larger sizes compared to that of Caucasians ${ }^{14-16}$. This may be due to a higher serum testosterone level in blacks ${ }^{17}$ or may be a reflection of late presentation. Yet awareness and demand for the procedure has risen fueled by the patient's perception of high postoperative morbidity and mortality associated with open prostatectomy.

Given these challenges, we set out to review our experience with TURP with a view to determining its efficacy and safety and to contribute to the growing debate about the current status of the procedure.

\section{Materials and Methods}

This is a retrospective survey of forty three patients who underwent transurethral resection of the prostate (TURP) for bladder outlet obstruction due to enlarged prostate. Spinal anaesthesia was employed routinely. 5\% Dextrose/water at a height of $60 \mathrm{~cm}$ from the bladder was used as an irrigation fluid. Preliminary cystoscopy was done with size 22F Karl Storz 30 degree cystoscope to assess the size and configuration of the prostate to determine the appropriateness of the modality and to rule out any other concomitant bladder pathology such as bladder stone that may alter the therapeutic approach. Patients whose glands where of such a size and/or configuration as to prevent the successful introduction of the cystoscope or resectoscope into the bladder were excluded and offered open prostatectomy. TURP was accomplished with size 26F Richard Wolf double channeled resectoscope using a cutting and coagulating current of $150 \mathrm{~W}$ and $90 \mathrm{~W}$ respectively. A 3 way Foley's urethral catheter was installed at the end of the procedure for the purpose of bladder irrigation. Bladder irrigation was done continuously with normal saline until cessation of active bleeding. Removal of catheter and voiding trial was done $6 \mathrm{hrs}$ after the discontinuation of irrigation.

The following parameters were extracted from the records and analyzed with Microsoft excel work sheet: Age, preoperative serum prostate specific antigen (PSA) values, prostate size (as determined at abdomino-pelvic ultrasound), indications for surgery, duration of surgery, duration of hospital stay, complications and outcome.

\section{Results}

The age range was $4976 \mathrm{yrs}$ (mean 65+/-5.8SD). The serum prostate specific antigen (PSA) ranged from 1.3 to $50.3 \mathrm{ng} / \mathrm{ml}$ (mean $13.3+/-12.8 \mathrm{SD}$ ). The mean prostate size was $59 \mathrm{~g}+/-20$ SD (range $2798 \mathrm{~g}$ ). Normal preoperative serum electrolytes, urea and creatinine and serum glucose levels were prerequisites for surgery. Serum electrolyte and glucose profiles were not routinely measured postoperatively unless there are specific indications. The relative frequencies of the indications for surgery are depicted in table 1.Duration of surgery was between 60 and 90mins (80.5+/-14SD). Duration of hospital stay was between 332 days (mean $8.7+/-7.7 \mathrm{SD}$ ). The complication profile is represented in table 2. Patients that required blood transfusion received an average of two pints of blood. All but two patients had satisfactory voiding and insignificant post void residual urine volume on discharge and subsequent follow up visits.

Table 1: Indications for Surgery.

\begin{tabular}{lll}
\hline Indications & No of patients & \% \\
\hline Refractory AUR & 21 & 49 \\
Failed medical treatment & 9 & 21 \\
Recurrent UTI & 7 & 16 \\
Recurrent haematuria & 4 & 9 \\
Chronic urinary retention & 1 & 2 \\
\hline
\end{tabular}

Table 2: Complications of Surgery.

\begin{tabular}{lll}
\hline Complications & No of patients & \% \\
\hline Bleeding & 17 & 40 \\
Capsular tear & 2 & 4.6 \\
TURP syndrome & 2 & 4.6 \\
Total incontinence & 1 & 2 \\
Failure to void & 2 & 4.6 \\
Death & 1 & 2 \\
\hline
\end{tabular}

\section{Discussion}

Transurethral resection of the prostate enjoys a very wide acceptability among men with symptomatic $\mathrm{BPH}$. This is evidenced by the increase in number of 
patients who presented for surgery as soon as we started offering the services.

The age range of $4976 \mathrm{yrs}$ is keeping with the age group afflicted by the two major conditions for which this treatment modality was offered.

The very wide variation in the serum PSA is not unexpected since our series included a diverse group of patients ranging from those with benign to malignant glands.

Traditionally, the size of the prostate gland has been the limiting factor in the application of the procedure. Glands that are more than $75 \mathrm{~g}$ are usually reserved for open prostatectomy ${ }^{1,5}$. We were able to accomplish this procedure in patients with glands weighing as much as $98 \mathrm{~g}$ without any untoward effects. Gupta et al published a series with a median weight of $54 \mathrm{~g}{ }^{18}$. Tan et al operated on a much wider range $(40-200 \mathrm{~g})$ with good results ${ }^{19}$. The two major concerns about the resection of large glands are haemorrhage and occurrence of TURP syndrome. Our transfusion rate of $40 \%$ is relatively high and this is probably due to a relatively large mean prostate size and the inclusion of cases done in the initial part of the learning curve. From our experience, blood loss can be markedly minimized if coagulation is done after 'digging every trough' instead of waiting till the end of the entire procedure. TURP syndrome on the other hand can be prevented to a very large extent by avoiding any tendency towards undermining the bladder trigone and capsular perforation. This can be achieved by keeping the cutting motion straight ${ }^{20}$. We are of the view that it is the configuration primarily and to a lesser extent the size of the prostate that should guide the resectionist in decision making between endoscopic and open techniques. In other words, the potential for success is almost always there so long as the resctoscope can be advanced into the bladder. Even when the size of the gland is such that would warrant an unduly prolonged operation time, staged TURP can be done

Furthermore minimal TURP has been shown to have the same efficacy as total TURP ${ }^{2}$. These options are rather attractive in our subregion where we tend to see patients with relatively large glands.

There was a positive correlation between the size of the prostate and the duration of surgery and hospital stay 0.9 and 0.2 respectively. The operation time (60$120 \mathrm{mins}$ ) is similar to that reported by Alhassan et al in Kano who reported duration of $20-120 \mathrm{mins}^{21}$. The causes of long post operative stay in our series were mainly capsular perforation and the presence of co morbidities such as diabetes and chronic renal failure.
The complication profile is similar to that reported by both Gupta et al and Alhassan et al ${ }^{18,21}$. Only 2 patients developed TURP syndrome. Incidentally, these were the same patients who had capsular perforation. We think that the technique (i.e. keeping the cutting motion straight) much more than the size of the gland and the duration of resection should be the key to the prevention of TURP syndrome ${ }^{20}$. Total incontinence occurred in one patient with advanced CAP. We make it a point to warn such patients of this possibility which may occur not necessarily from the procedure but from the disease process i.e. local infiltration of the external urinary sphincter by the tumour ${ }^{22,23}$. Two patients were unable to void. One of them had an incomplete resection that required a repeat TURP and the other apparently had detrusor failure. The only mortality recorded 2 weeks post op was not directly related to the procedure. The patient was undergoing dialysis for symptomatic azotemia but had emergency TURP on account of massive haematuria. Otherwise every other patient reported satisfactory voiding and had insignificant post void residual urine volume on discharge and subsequent follow up visits.

\section{Conclusion}

TURP remains a safe and effective remedy for patients with BOO secondary to BPH and advanced CAP as well. With good technique, it can be accomplished with very low rates of morbidity and mortality.

\section{References}

1. Fitzpatrick JM, Mebust WK. In: Minimally invasive and endoscopic management of benign prostatic hyperplasia. Walsh $\mathrm{PC}$, Retic $\mathrm{AB}$, Vaughan ED Jr, Wein AJ (Ed) Campbell's urology. 8. Philadelphia, W.B Saunders company, 2002.

2. Madersbacher S, Marberger M. Is transurethral resection of the prostate still justified? BJU International 1999: 83; 227-237.

3. Bardos A, Hornak M, Novotny V. Transurethral resection of the prostate in the treatment of benign prostatic hyperplasia. Bratisl Lek Listy. 2001:102(2);79-83.

4. Küpeli S, Yilmaz E, Soygür T, Budak M. Randomized study of transurethral resection of the prostate and combined transurethral resection and vaporization of the prostate as a therapeutic alternative in men with benign prostatic hyperplasia. J Endourol. 2001 Apr; 15(3):317-21.

5. Noguera RS, Rodríguez RC. Open adenomectomy: past, present and future. Curr Opin Urol. 2008 Jan; 18(1):34-40. 
6. Herrmann TR, Georgiou A, Bach T, Gross AJ, Oelke M. Laser treatments of the prostate vs TURP/ open prostatectomy: systematic review of urodynamic data. Minerva Urol Nefrol. 2009 Sep; 61(3):309-24.

7. Thiel DD, Petrou SP. Electroresection and open surgery. Urol Clin North Am. 2009 Nov; 36(4):461-70, vi.

8. Horninger $\mathrm{W}$, Unterlechner $\mathrm{H}$, Strasser $\mathrm{H}$, Bartsch G. Transurethral Prostatectomy: Mortality and Morbidity. The Prostate 1996: 28; 195-200.

9. Crain DS, Amling CL, Kane CJ. Palliative transurethral prostate resection for bladder outlet obstruction in patients with locally advanced prostate cancer. J Urol. 2004 Feb; 171(2 Pt 1):668-71.

10. Sehgal A, Mandhani A, Gupta N, Dubey D, Srivastava A, Kapoor R, Kumar A. Can the need for palliative transurethral prostatic resection in patients with advanced carcinoma of the prostate be predicted? J Endourol. 2005 Jun; 19(5):546-9.

11. Tuhkanen K, Heino A, Aaltomaa S, Ala-Opas M. Long-term results of contact laser versus transurethral resection of the prostate in the treatment of benign prostatic hyperplasia with small or moderately enlarged prostates. Scand J Urol Nephrol. 2003; 37(6):487-93.

12. Herrmann TR, Georgiou A, Bach T, Gross AJ, Oelke M. Laser treatments of the prostate vs TURP/open prostatectomy: systematic review of urodynamic data. Minerva Urol Nefrol. 2009 Sep; 61(3):309-24.

13. Hoffman RM, Monga M, Elliot SP, Macdonald R, Wilt TJ. Microwave thermotherapy for benign prostatic hyperplasia. Cochrane Database Syst Rev. 2007 Oct 17 ;(4):CD004135.

14. Henderson RJ, East JA, Culkin DJ. Prostate specific antigen and PSA density: racial differences in men without prostate cancer. J Natl Cancer Inst. 1997: 89; 134-138.
15. Dalin HE, Mingzhu W, Xingfa C, Zhongwei G, Hui HE, Haiyen EZ et al. Ethnic differences in distribution of serum prostate specific antigen: a study in a healthy Chinese male population. Urology 2003: 63; 722-726.

16. John CM, Alan WP, Christopher LA, Martha KT, Christopher JK, William JA et al. Do racial differences in prostate size explain higher serum prostate specific antigen concentrations among black men? Urology 2007: 69; 1138-1142.

17. Ross R, Bernstein L, Judd H. Serum testosterone level in healthy young black and white men. $\mathrm{J}$ Natl Cancer Inst 1986: 76; 45-48.

18. Gupta NP, Doddamani D, Aron M, Hemal AK. Vapor resection: a good alternative to standard loop resection in the management of prostates . 40 cc. J Endourol. 2002 Dec; 16(10):767-71.

19. Tan AH, Gilling PJ, Kennett KM, Frampton C, Westenberg AM,Fraundorfer MR. A randomized trial comparing holmium laser enucleation of the prostate with transurethral resection of the prostate for the treatment of bladder outlet obstruction secondary to benign prostatic hyperplasia in large glands (40 to 200 grams). J Urol 2003; 170:1270-1274.

20. Alemu MH. Transurethral resection of the prostate (TURP)--in the treatment of benign prostatic hypertrophy (BPH) in Mekelle, Ethiopia. Ethiop Med J. 2009 Jan; 47(1):65-9.

21. Alhasan SU, Aji SA, Mohammed AZ, Malami S. Transurethral resection of the prostate in Northern Nigeria, problems and prospects. BMC Urol. 2008 Dec 6; 8:18.

22. Mazur AW, Thompson IM. Efficacy and morbidity of "Channel" TURP. Urology 1991: 38(6); 526-528.

23. Kollmeier MA, Stock RG, Cesaretti J, Stone NN. Urinary morbidity and incontinence following TURP after brachytherapy. J Urol 2005: 173(3); 808-812. 